\title{
Mechanical and Typological Characterization of Traditional Stone Masonry Walls in Old Urban Centres: A Case Study in Viseu, Portugal
}

\author{
José Carlos Domingues ${ }^{1}$, Tiago Miguel Ferreira ${ }^{2, *}$, , Romeu Vicente $^{3}$ and João Negrão ${ }^{4}$ \\ 1 Department of Civil Engineering, University of Coimbra, 3030-788 Coimbra, Portugal; \\ jcarl.domingues@gmail.com \\ 2 ISISE, Institute of Science and Innovation for Bio-Sustainability (IB-S), Department of Civil Engineering, \\ University of Minho, 4800-058 Guimarães, Portugal \\ 3 RISCO, Department of Civil Engineering, University of Aveiro, 3810-193 Aveiro, Portugal; romvic@ua.pt \\ 4 Department of Civil Engineering, University of Coimbra, 3030-788 Coimbra, Portugal; jhnegrao@dec.uc.pt \\ * Correspondence: tmferreira@civil.uminho.pt; Tel.: +351-253-510-200
}

Received: 19 December 2018; Accepted: 4 January 2019; Published: 9 January 2019

\begin{abstract}
Essential for any intervention in existing buildings, a thorough knowledge of both structural and material characteristics is even more important in the case of traditional stone masonry buildings, due both to the variability of this technology's properties and the degradation buildings might have sustained. In Portugal, a number of in situ and laboratory experimental campaigns has allowed us in recent years to expand the knowledge on the mechanical properties of stone masonry walls. Nevertheless, the existence of different wall typologies built with the same material necessitates that this characterization takes into account the various regional constructive cultures. This paper presents the results obtained through an in-situ characterization campaign carried out in the old urban center of Viseu, for which there is no information available in the literature. Granite stone masonry walls of two different buildings were analyzed and characterized considering their geometrical and material features, contributing to the identification of stone masonry typologies present in the city's old urban center. Flat-jack testing yielded resistance and deformability parameters to be used both in safety evaluation and intervention design. The properties obtained can be said to be consistent with those deriving from other experimental campaigns, conducted in granite walls of different typologies, throughout the country. Simultaneously, relevant conclusions about the use of flat-jacks to characterize this type of stone masonry were drawn.
\end{abstract}

Keywords: masonry characterization; mechanical properties; in situ test campaign; granite masonry; flat-jack testing; old urban center; regional constructive cultures

\section{Introduction}

When intervening in existing buildings, and with a view to preserving historical and material authenticity, no action should be conducted without being absolutely necessary. To ensure this, a deep knowledge of structural and material characteristics, constructive technologies and techniques, changes made over time, and current state of the building is fundamental [1]. This necessity is all the more pressing when dealing with stone masonry buildings, as their structural behavior is significantly different from recent buildings (generally consisting of reticulated reinforced concrete structures), besides also presenting high typological and mechanical variability, which are quite dependent of the local material availability and constructive tradition.

The characterization of the mechanical behavior of granite stone masonry, a typology common in the North and Center-North of Portugal, has already been the subject of some studies conducted 
both in situ [2,3] and in laboratory [4-7]. Nevertheless, the existence of various regional constructive cultures, resulting in different wall typologies built with the same material, leads to the need for such characterization to take into account the specific locations where these walls are representative. Regarding the specific case of the city of Viseu, it is worth mentioning that information concerning the mechanical properties of granite stone masonry walls in its old urban center is absent. Therefore, and aiming at providing data that can help to retain the original structural system of these buildings, while ensuring structural safety, this work intends to offer a first contribution to the characterization of these elements. It is intended, namely, and apart from geometrical and material characterization which can contribute to the identification of stone masonry typologies frequent in the old urban center of Viseu, to quantify resistance and deformability parameters to be used both in safety evaluation and intervention design. Thus, this paper presents and discusses the results obtained from an in situ test campaign conducted in the old urban center of Viseu. Granite stone masonry walls of two different buildings were analyzed and characterized considering their geometrical and material characteristics. Flat-jack testing technique was used to obtain resistance and deformability parameters to be used both in safety evaluation and intervention design. Relevant conclusions about the use of flat-jacks to characterize this type of stone masonry were also drawn.

\section{The City of Viseu: Brief Urbanistic and Constructive Characterization}

The city of Viseu plays an important role in the history of Portugal, as it is markedly linked to the figure of Viriathus, a tribal leader who resisted the Roman invasion. In fact, since Roman times, Viseu has assumed a prominence in the nearby settlements. Following the ancient Roman urbanistic tradition, the city developed around two main roads, the cardus, oriented North-South, and the decumanus, oriented East-West. This influence can still be seen today, as both roads evolved to be prominent axis of the city's old urban center (Figure 1).

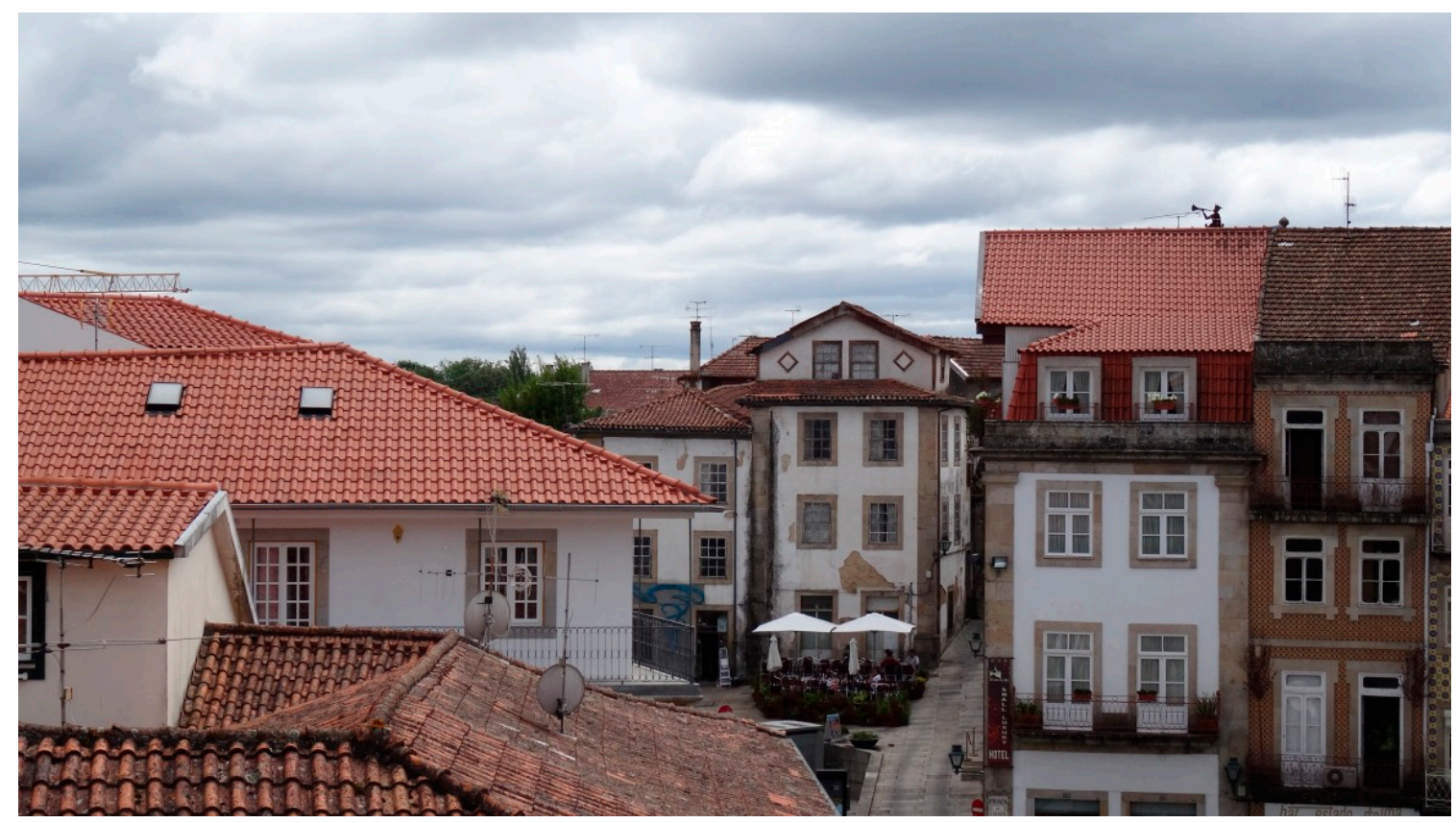

Figure 1. View of the old urban center of Viseu.

It was during the XVI century that Viseu started expanding outwards towards its ancient walls. It was also by this time that the area nowadays known as Rossio started gaining importance; by the XIX century, it would have become the new civic center of the city, with the construction of the town hall building. Nowadays, with 73,518 inhabitants in its urban perimeter [8], Viseu is the second biggest 
city in the Região Centro of Portugal, as well as the largest urban center outside both metropolitan areas and the littoral of the country.

As to the constructive system of the buildings from the old urban center of the city of Viseu, namely in what pertains to the vertical resisting elements, the abundance of granite stone makes this the most common material with which to build masonry walls, as is common in the Northern Region of Portugal. The granite used in the construction of the traditional masonry buildings of the old urban center of Viseu came from different quarries between the Douro and Mondego rivers. The larger and well-cut granite stone blocks were used in the construction of churches, palaces (today museums), cathedrals since they were not covered or rendered. The fragmented granite stone was commonly used for traditional building construction from one to four stories high inside the city walls. Nevertheless, and despite its abundance, no information related to the mechanical properties of granite stone masonry walls from the old urban center of Viseu exists in the literature. Besides stone, different materials and constructive processes can be found, namely timber "tabique" walls for the inner (often non-resisting) walls, or "taipa", an earth-based material, for the walls in the upper floors.

Aiming at safeguarding and potentiating the city's cultural heritage, both tangible and intangible, the Viseu City Council has recently promoted the project Viseu Património. It is in this scope that the campaign described in this paper was conducted.

\section{Typological, Geometrical and Material Characterization of Stone Masonry Walls}

Due to its architectural and historical significance, the buildings studied in this campaign (named Orfeão de Viseu and Águas de Viseu) have been selected by the City Council to be part of the first phase of the project Viseu Património, within the framework of which they will be object of intervention resorting to the "best practices" in heritage conservation. The main objective is that these two buildings/interventions can become models of interventions for future conservation and rehabilitation works in the old urban center of Viseu.

Figure 2 shows the location of these buildings in the old urban center of the city. In the following subsections, each building is briefly described, and the geometrical and material characteristics of the walls studied in each one of them are presented.

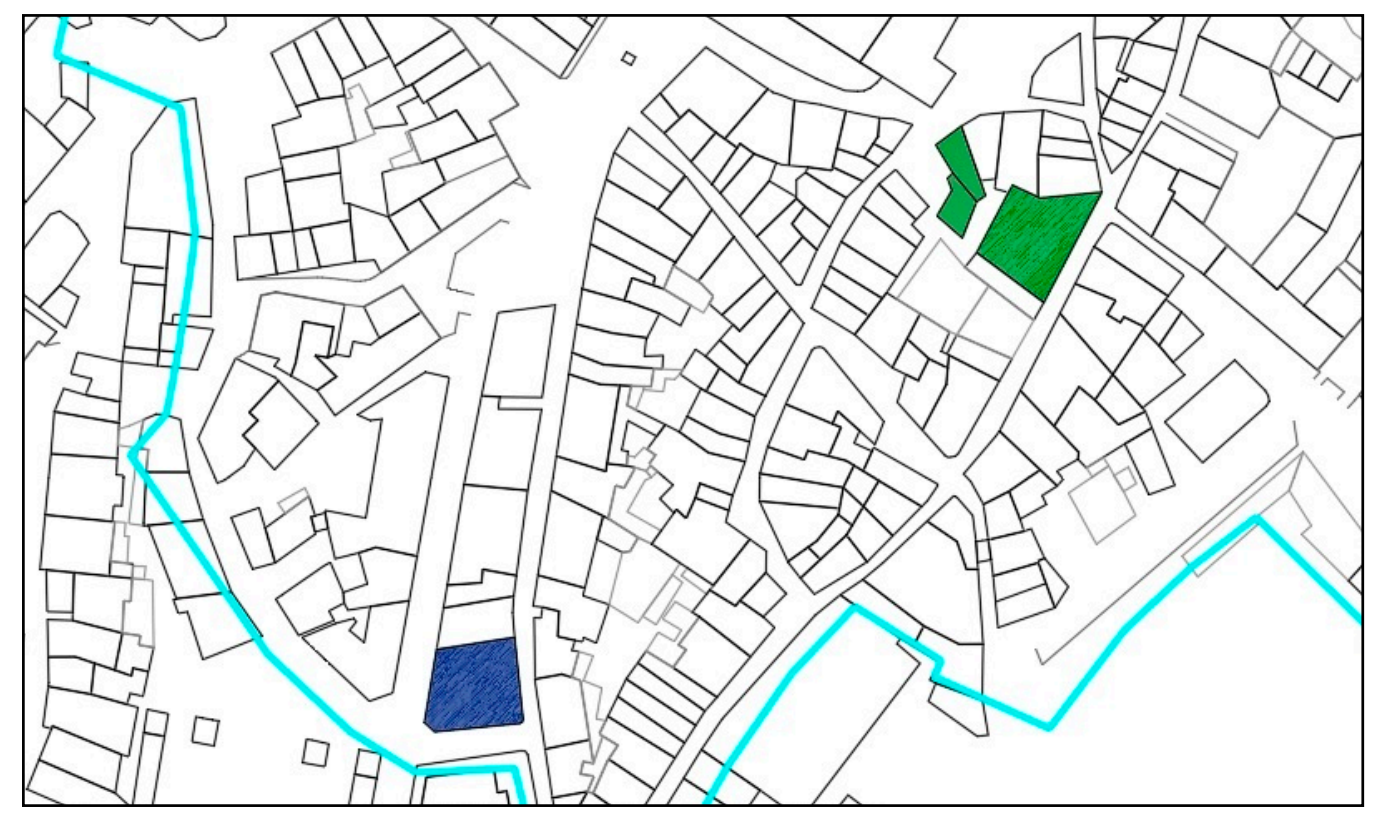

Figure 2. Buildings studied in this campaign: Orfeão de Viseu (green) and Águas de Viseu (dark blue). The light blue line marks the old urban center's limit (adapted from map kindly made available by the Viseu Urban Rehabilitation Society Viseu Novo). 


\subsection{Orfeão de Viseu}

The building located in the number 149 of Rua Direita (the ancient commercial artery in the city) housed between 1955 and 2006 the headquarters of Orfeão de Viseu, a cultural society dedicated to arts and music. Structurally, the building follows the traditional constructive technology, with load-bearing stone masonry walls and timber floors and roofs. Of unusually large dimensions for the area in which it is located, it is known that it was partially rebuilt after a fire in 1926 [9]. Figure 3 presents the main façade of the building, as well as the plans of the ground floor and the first floor.

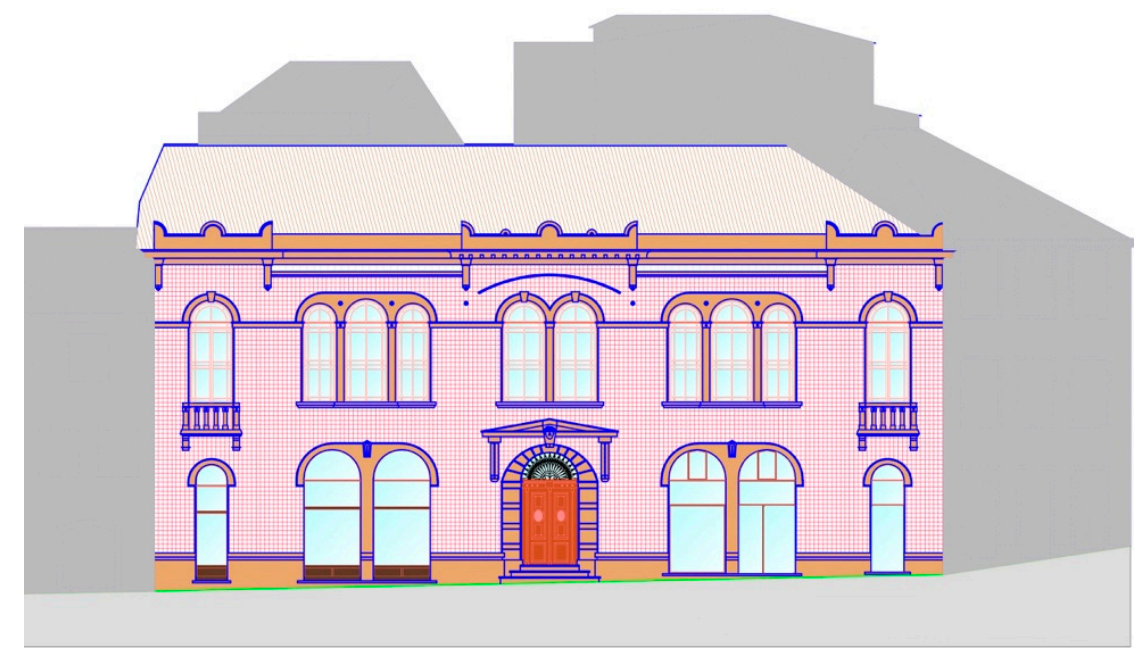

(a)

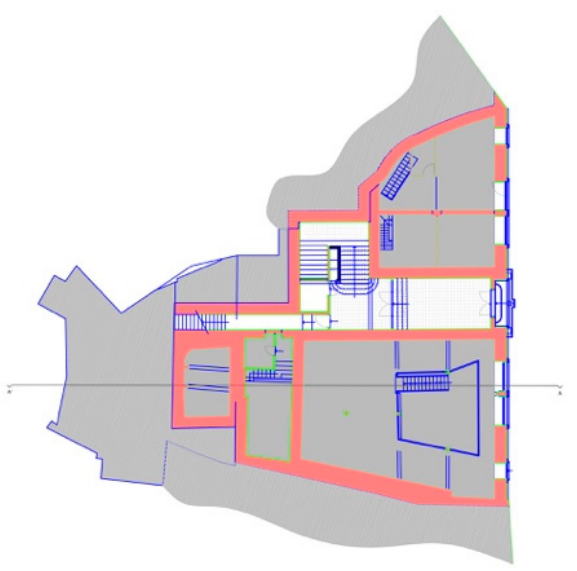

(b)

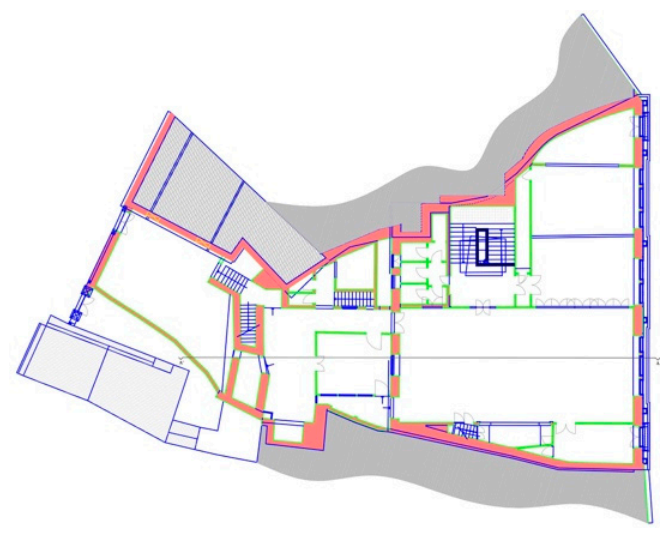

(c)

Figure 3. Orfeão de Viseu: (a) main façade of the building, (b) plan of the ground floor and (c) the first floor.

In its interior, it is worth mentioning the stairs, with a balustrade in wrought iron, and the stairwell covered with flower motive tiles, dating from 1912 (Figure 4). In the main hall, located in the first floor, it is possible to observe railroad tracks that were used as part of the walls' structural system. As for the partition walls, and apart from stone masonry, "tabique" walls are present. The presence of a structurally elaborate timber roof is also worth mentioning. 


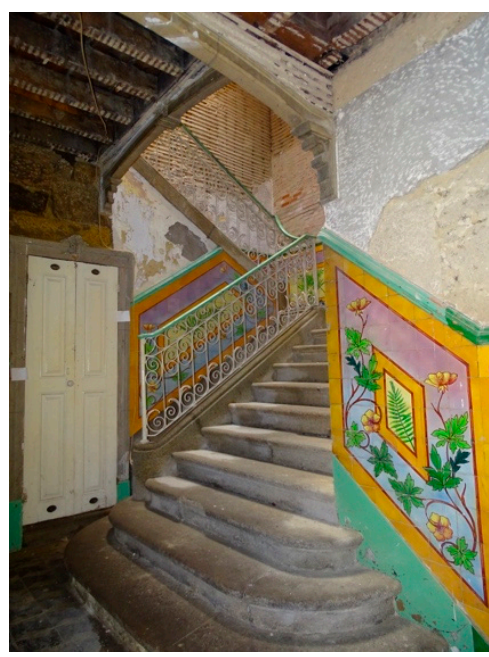

(a)

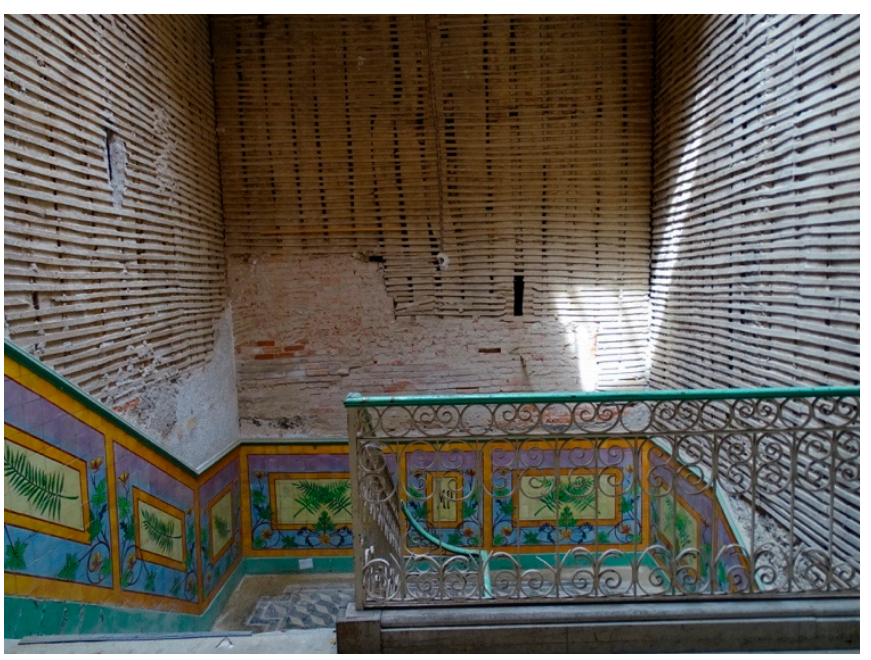

(b)

Figure 4. View to (a) the staircase with the tiles; and (b) the "tabique" walls.

A $50 \mathrm{~cm}$ thick interior load-bearing wall, located in the main hall and parallel to the main façade, was studied in this building, Figure $5 \mathrm{a}$. As can be seen in Figure $5 \mathrm{~b}$, stone masonry was visible without the need to remove any plaster. The masonry consists of gray granite stones, with both rectangular and square shape, and cream color mortar. In general, a length of around $70 \mathrm{~cm}$, for the biggest rectangular stones, and around $20 \mathrm{~cm}$, for the square ones, can be observed. Rectangular stones present a length/height ratio of approximately 3 . The presence of wedges was not significant.

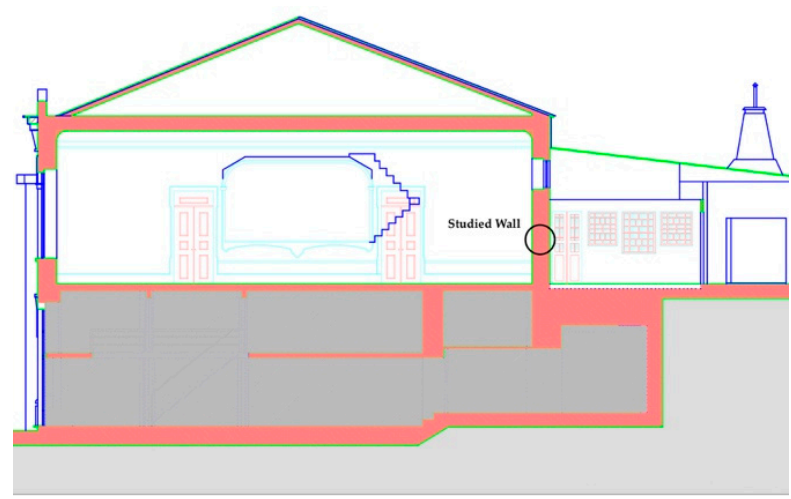

(a)

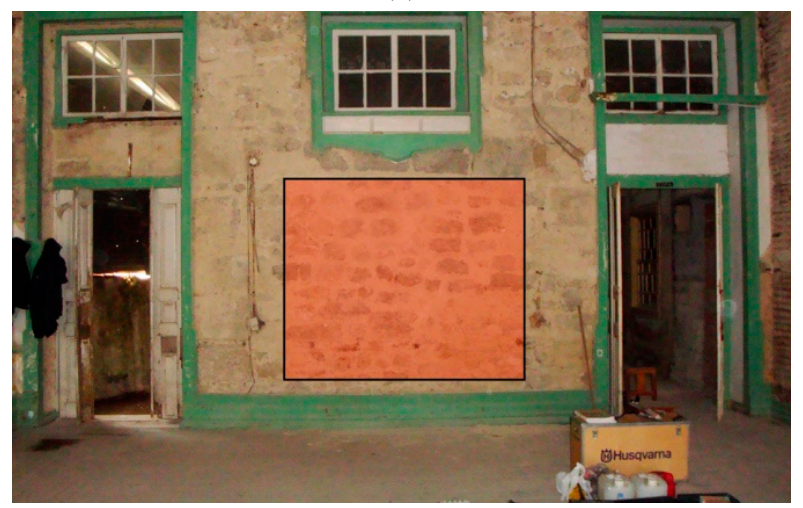

(b)

Figure 5. Identification of the studied wall. (a) location in the building; (b) testing area. 
Due to access limitations, it was not possible to observe the inner side of the wall, and thus it was not possible to infer about the existence of multiple leaves and/or through stones. It must be pointed that, due to repointing, the apparent dimension of the stones may not correspond to their actual dimension, as a result of mortar overlapping along their contour. As for the cross-section, the wall was found to be composed of two leaves, with a poor to reasonable degree of connection. The existence of an inner core, of weaker quality, was in any event ruled out. This last conclusion was further reinforced by the observation, resorting to videoscopy, of another wall's interior in the same room.

\section{2. Águas de Viseu}

The building dates back to the 1920s, and has three fronts, facing Rua Dr. Luís Ferreira (the ancient Rua do Comércio), Rua D. Duarte and Travessa de São Domingos (Figure 6). Besides the ground floor, it counts three floors and an underground basement.

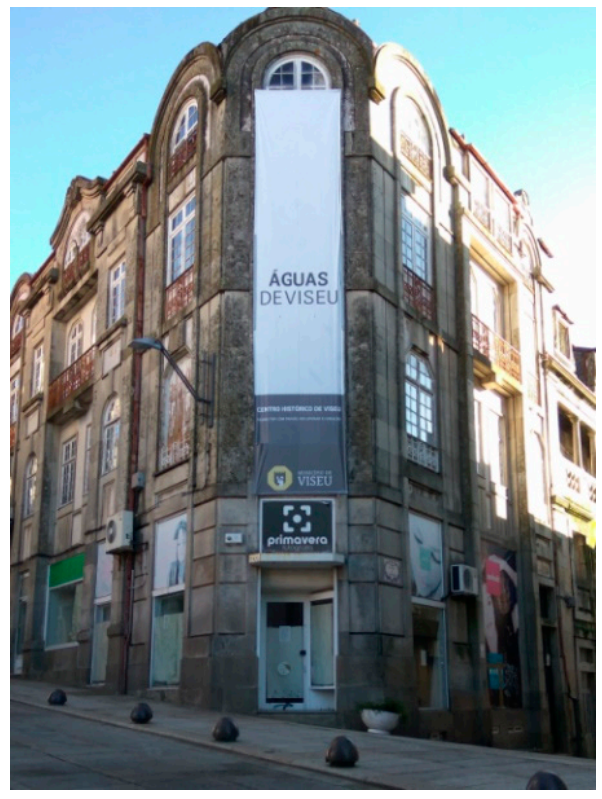

(a)

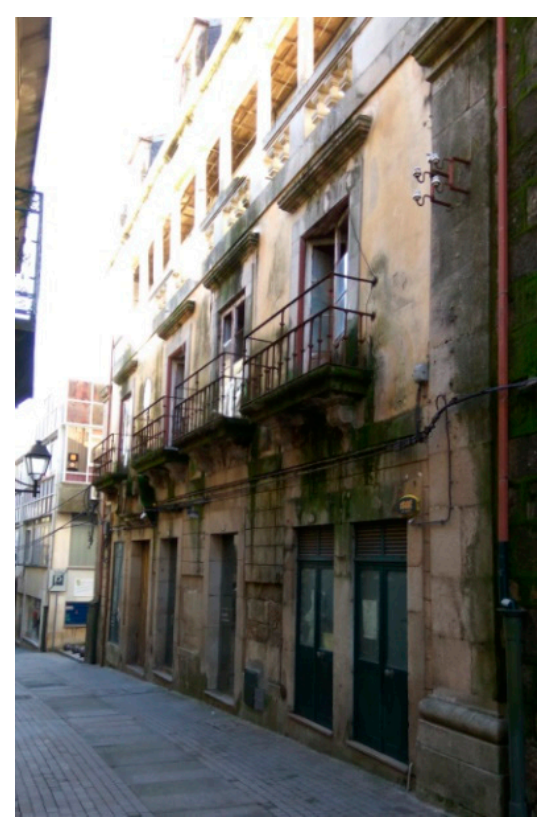

(b)

Figure 6. Águas de Viseu: (a) view to Rua do Comércio; and (b) view to Rua D. Duarte.

Despite it being classified as a structure with "relevant architectural and heritage value", the building is presently in an advanced state of degradation, see Figure 7.

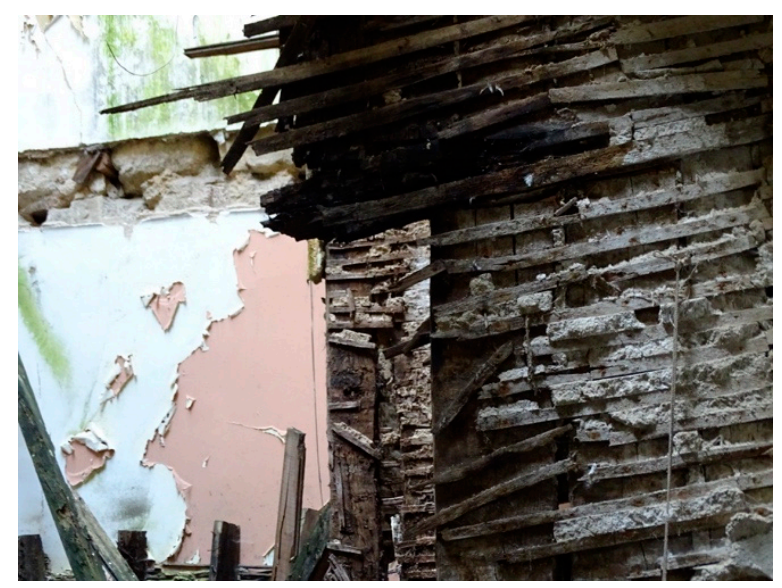

Figure 7. Cont. 


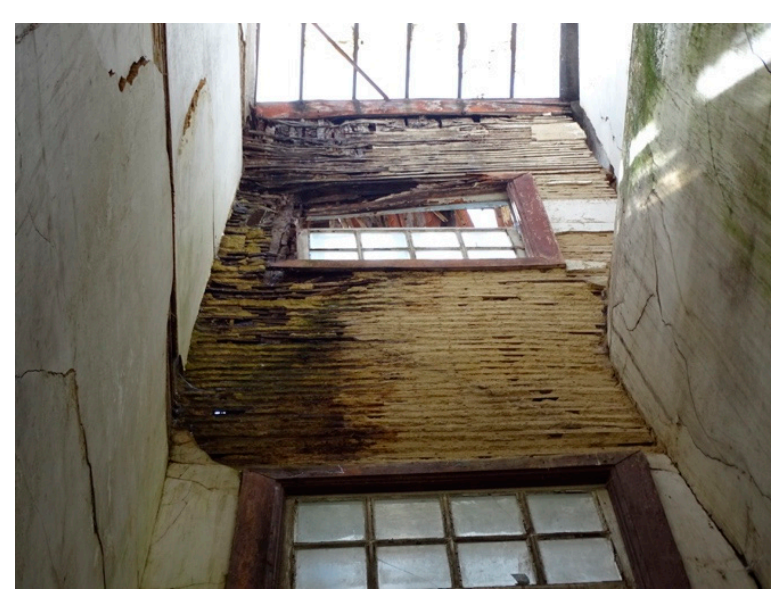

Figure 7. Severely decayed structural elements.

As in the previous case study, an internal load-bearing wall was studied, this time located at the ground floor and perpendicular to the façade facing Rua D. Duarte, Figure 8a. As can be seen in Figure 8b, also in this case, stone masonry was visible without the need to remove any plaster. Due to the presence of different minerals, such as quartz, mica and feldspar, stones present various colors, ranging from gray to yellow and pink. The mortar, of a gray color, appears to evidence recent repointing. Stones were rather irregular, both in shape and dimensions. The assemblage was markedly irregular, at times with stones laid with their larger dimension alongside the vertical. The presence of wedges was not significant.

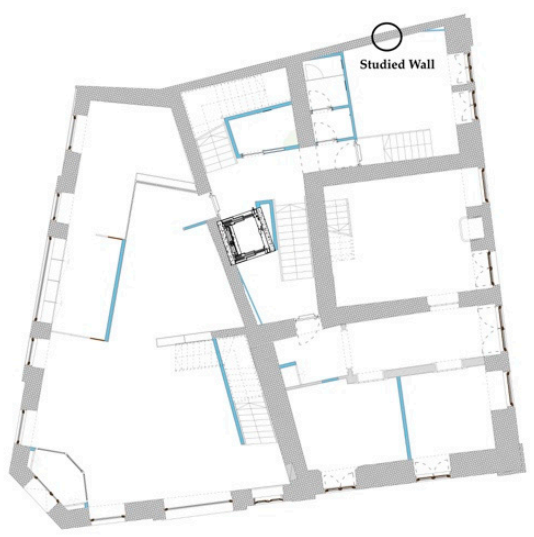

(a)

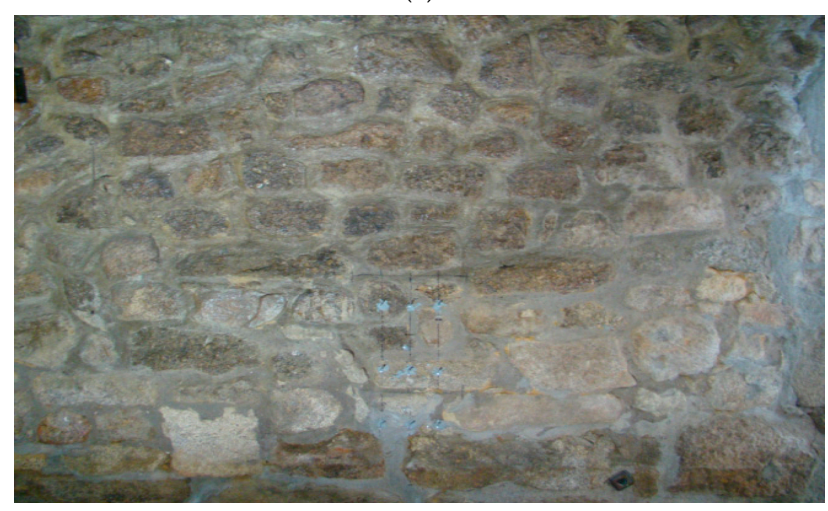

(b)

Figure 8. Águas de Viseu: (a) building plan with the identification of the studied wall; (b) view to the wall. 
The wall was found to be composed of two leaves, with an interior non-cohesive core (sacco masonry). Both the interior leaf and the inner core are $25 \mathrm{~cm}$ thick. It was not possible to measure the outer leaf thickness, but a $25 \mathrm{~cm}$ thickness is equally plausible. A total thickness of $75 \mathrm{~cm}$, at ground level, would then be expected. Regarding the inner core, it was possible to observe that the wall was filled with roughly-shaped granite stones of about $10-15 \mathrm{~cm}$ long, laid in a random manner (Figure 9a), linked by lime mortar and earth (Figure 9b). Some small wooden elements, such as wood splinters, were also found in the inner core of the masonry wall, see Figure 9c.

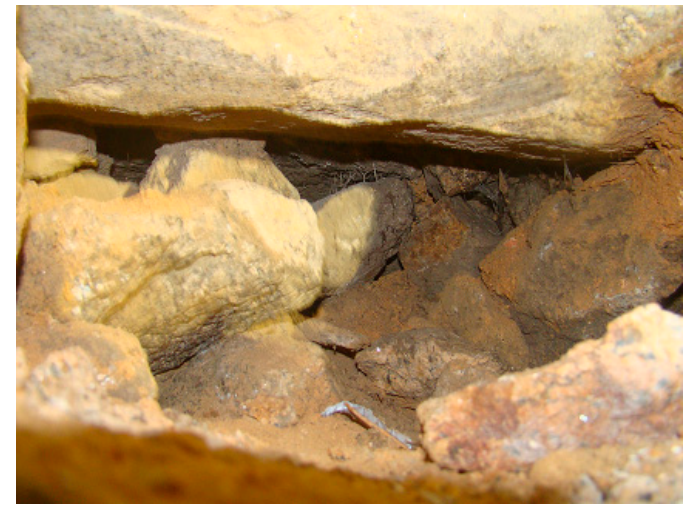

(a)

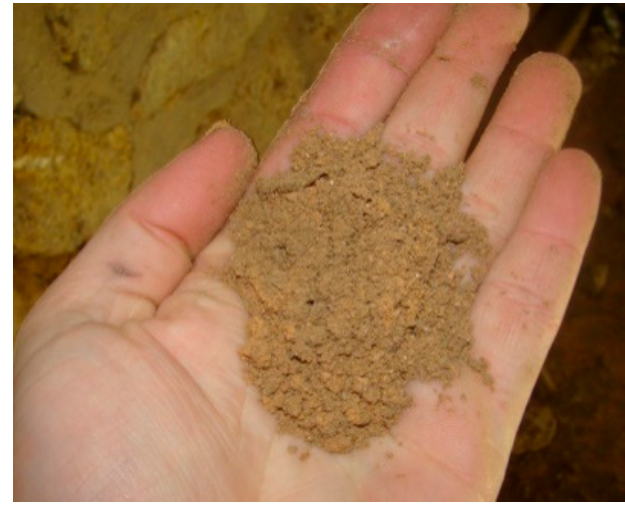

(b)

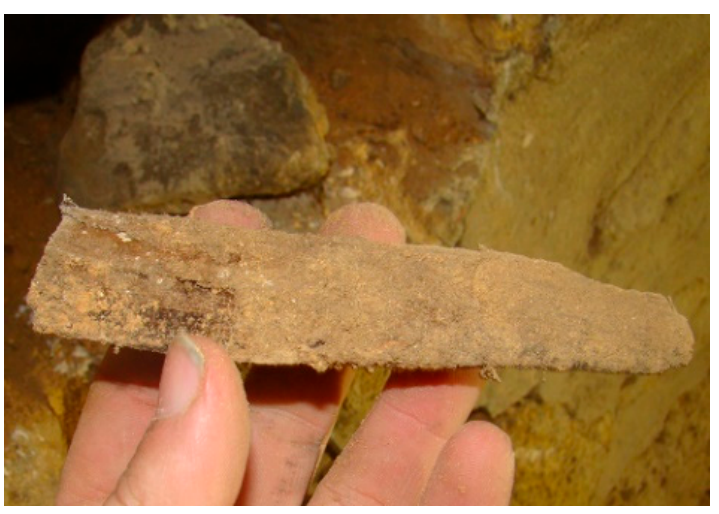

(c)

Figure 9. Wall's inner core. (a) roughly-shaped granite stones; (b) lime mortar and earth; (c) wood splinters.

\subsection{Mechanical and Visual Characterisation of the Stone}

The need to locally disassemble the masonry required collecting some granite stones as well, which could be then used to perform mechanical characterization tests in laboratory, namely to estimate their compressive strength. For this purpose, one sample of granite stone was extracted from the wall and prepared in laboratory to perform a uniaxial compression test, which took place in the Laboratory of the Civil Engineering Department of the University of Aveiro, Portugal, following the Portuguese standard NP EN 1926 [10].

Figure 10 presents the test sample, the test procedure and the final appearance of the sample after tested. The results obtained in the compressive test are presented in Table 1, where L, D, $\mathrm{m}$ and $\gamma$ stand respectively for the length, diameter, mass and specific weight of the test specimen and fcb is the maximum compressive strength recorded in the compressive test. 


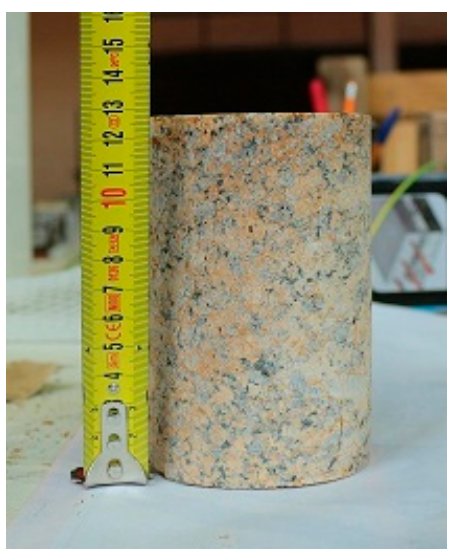

(a)

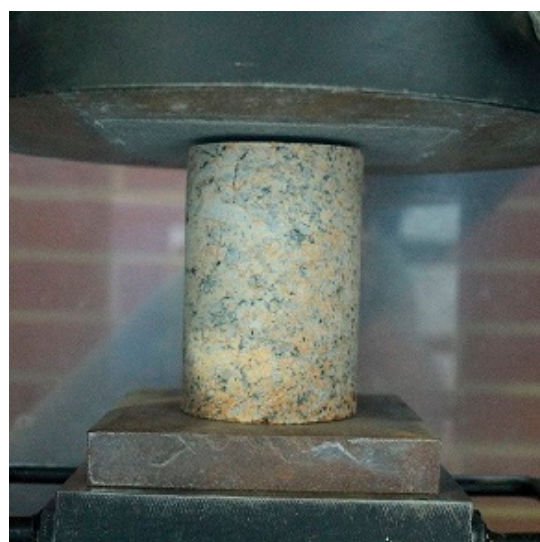

(b)

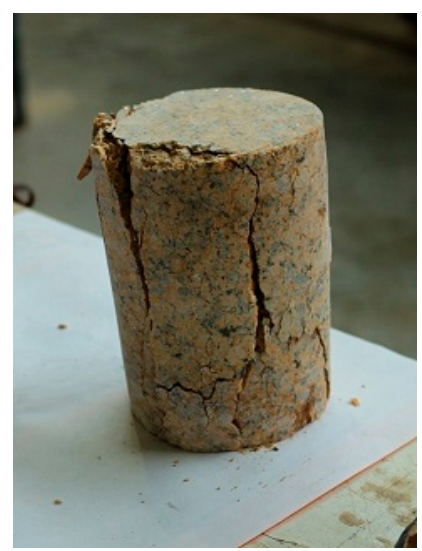

(c)

Figure 10. Compression test. (a) stone specimen; (b) experimental apparatus; (c) appearance of the specimen after the test.

Table 1. Results of compression tests.

\begin{tabular}{ccccc}
\hline $\mathbf{L}(\mathbf{m m})$ & $\mathbf{D}(\mathbf{m m})$ & $\mathbf{m}(\mathbf{k g})$ & $\gamma\left(\mathbf{k N} / \mathbf{m}^{3}\right)$ & $\mathbf{f}_{\mathrm{cb}}\left(\mathbf{N} / \mathbf{m m}^{2}\right)$ \\
\hline 126 & 84 & 1.77 & 24.85 & 32.7 \\
\hline
\end{tabular}

Despite being low, the value of compressive strength obtained can be considered to be consistent with the range of values expected for ancient granites [4,11]. It is however important to stress that since only one sample could be tested (due to several constraints, namely related with the extraction of stone material in quantity and with enough quality/integrity to be tested in lab) the representativeness of the result is not fully guaranteed. Even so, this result was important to identify current state of meteorization of this granite and to better understand its mechanical characteristics, which is considered a relevant output since no other similar tests could be found in the literature for the granite present in the old urban center of Viseu.

Visual analysis of the granite samples showed the simultaneous occurrence of various types of granite. It was possible to note the existence both of coarse-grained porfiroid granite, composed of biotite, muscovite and feldspar fenocrystals, as well as of medium-grained gneissic granite, also composed of biotite and muscovite. In both types, weathering was observed, namely in the yellow coloration around the biotite crystals, signaling the oxidation of ferrous oxides. This could help to explain the low compressive strength value obtained in the uniaxial test, as granites experience a reduction of strength when subject to this phenomenon [12].

Moreover, it is worth noting that compressive and shear strength of masonry are dependent on the masonry fabric and arrangement, mechanical properties of the stone, mortar and their percentage, 
as well as the presence of voids. Besides, it is important to underline the fact that the dimension of the stone blocks and their arrangement are responsible for the development of preferential and alternative load. Masonry walls with the lowest percentage of mortar and voids lead to the highest values of maximum stress and Elastic Modulus.

\section{Mechanical Characterization of Stone Masonry Walls Through Flat-Jack Technique}

Flat-jack testing is recognized as one of the most versatile techniques for the in situ characterization of the mechanical behavior of masonry walls under compression $[13,14]$. Through flat-jack testing it is possible, namely, to obtain information regarding the in situ stress level, as well as resistance and deformability characteristics. Because it involves only the execution of one or two cuts of small dimension and thickness, which can be filled after the test is finished, this technique is usually considered as a semi-destructive procedure.

Flat-jack technique has been widely and successfully applied in several past studies, namely in regular brick and stone masonry walls [15]. However, the use of this technique in irregular stone masonry has been the subject of relatively few studies [13,16-19]. In these walls, not complying with all standards' requirements is a contingency that must be taken into account. Among these, instructions regarding the minimum length of the jack, which is defined on the basis of the single masonry units' length, are often difficult to follow. In this regard, it is worth remembering that standards directing this procedure date back to the beginning of the 1990s, when this technique, already widely used in brick masonry, was still rarely applied in stone masonries, and especially in those with irregular morphology (as still today). Moreover, geometrical variability of stone masonry contributes for the low reliability of results obtained in a localized area in the wall [18]. Difficulty in finding regular mortar joints represents a further complexity when applying flat-jack in irregular masonries, as the cut(s) must then be made through the stones [20]. Geometrical characteristics of stone masonry also influence the choice of the points where measuring devices are to be located. Likewise, causing irregular distributions of stone and mortar, and, thus, areas with different behavior, they can cause localized anomalies through rotations of the devices, which influence the results. Besides these, the experience acquired through this campaign has allowed us to identify further limitations of the application of flat-jack testing to irregular masonries. It is acknowledged that a larger number of flat-jack tests is necessary to obtain more reliable results to better match with morphological and constitution features of masonry fabric. Complementarily, other non-destructive testing techniques, such as sonic tests, tube-jack testing as well as destructive testing techniques such as: shear tests, in-plane and out-of-plane testing, chemical tests, etc., should be considered and combined namely for structural evaluation and damage assessment of historical constructions.

In Portugal, flat-jack testing has been used in several studies, namely those conducted by Roque [21], Pagaimo [22], Vicente et al. [13], Ferreira [23], Miranda [3] and Simões et al. [19]. Nevertheless, taking into account the aim of the present paper, it must be noted that flat-jack testing campaigns aiming at characterizing granite stone masonry are still scarce.

\subsection{In Situ Experimental Campaign}

As already referred, flat-jack testing allows obtaining information regarding both the in situ stress level of the wall section as well as resistance and deformability characteristics. For this, different testing procedures are conducted, namely, the single and the double flat-jack test. These procedures are described in the American standards ASTM C1196-91 [24] and ASTM C1197-91 [25] and in the European recommendations RILEM MDT. D. 4 [26] and RILEM MDT. D. 5 [27].

\subsubsection{Single and Double Flat-Jack Testing}

Single flat-jack testing is based on determining the stress needed to restore the initial geometry of a wall, which has been disturbed by eliminating the wall's initial vertical stress by means of a horizontal cut. After this cut, and the corresponding lowering of the distance between reference points located, 
above and below, in the same vertical alignment transversal to the cut, a flat-jack is introduced in the slot and afterwards pressurized by means of a hydraulic system, so that stress is being transmitted to the surrounding masonry and the initial distance between reference points is eventually restored. The average existing stress level $\left(\sigma_{m}\right)$ can thus be computed as:

$$
\sigma_{m}=k_{m} \times k_{a} \times p
$$

where $k_{m}$ is a dimensionless factor taking into account the flat-jack rigidity, $k_{a}$ is the ratio between the area of the jack effectively in contact with the masonry and the total area of the jack, and $p$ is the pressure measured within the flat-jack.

Due to the anisotropic behavior of masonry, single flat-jack testing is not a suitable procedure for the determination of deformability properties. For this purpose, the double flat-jack testing, consisting of two vertically aligned flat-jacks introduced in parallel slots, is used. The portion of the wall located between the jacks can be thus tested under uniaxial compression, therefore obtaining a relatively reliable estimate of the Young's modulus (E) value from the stress-strain curve. Using a horizontal displacement transducer, it is further possible to compute the Poisson's ratio $(v)$.

According to ASTM C1197-91 [25], double flat-jack testing overestimates the value of the Young's modulus by 15 to $20 \%$. It must nevertheless be recalled that this value applies for brick masonry; it is to be expected that the deviation will be greater in stone masonry [14].

\subsubsection{Equipment and Testing Protocol}

The following equipment was used:

- Flat-jacks: BOVIAR MPA-A semicircular flat-jacks, with dimensions $350 \times 260 \times 4 \mathrm{~mm}$, and maximum service pressure 60 bar, Figure 11a. According to the calibration certificate, a $\mathrm{km}$ value of 0.902 was assumed for all the flat-jacks used in this campaign.

- Masonry cutting equipment: HUSQVARNA k970-Ring cutting machine, with a $300 \mathrm{~mm}$ eccentric diamond blade disk, allowing a cut depth of $270 \mathrm{~mm}$.

- Pressurizing equipment: manual hydraulic ENERPAC pump, with a 500 bar capacity and a $3 \mathrm{~L}$ reservoir, Figure 11b. The pressure applied is controlled using a pressure reading manometer. The hydraulic system and the flat-jacks are connected via high pressure hoses.

- Displacement transducers: GEFRAN displacement transducers, with a $50 \mathrm{~mm}$ stroke, provided with self-aligning ball-joints. The displacement transducers were attached to the masonry by means of $5 \mathrm{~mm}$ threaded rods, applied with chemical anchor, at a depth of $50 \mathrm{~mm}$, Figure 12.

- Data acquisition and log system, consisting of a load cell, a NATIONAL INSTRUMENTS acquisition unit, a laptop and acquisition software developed in the LabVIEW environment [28].

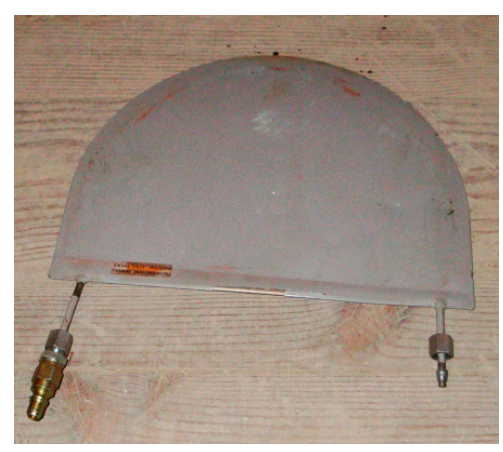

(a)

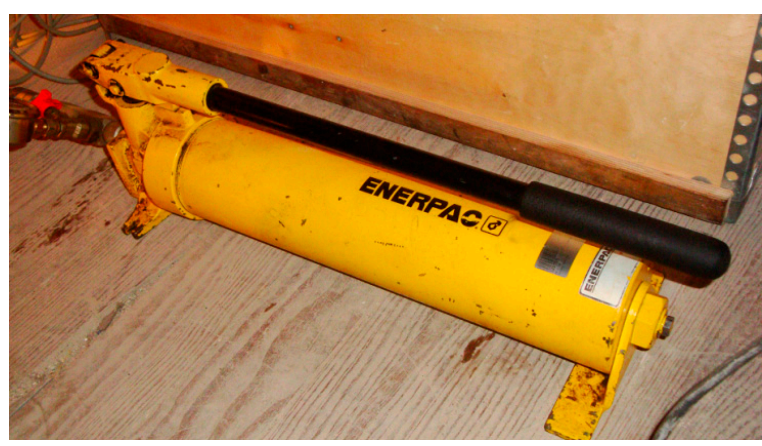

(b)

Figure 11. Equipment used in this campaign: (a) semicircular flat-jacks and (b) hydraulic pump. 


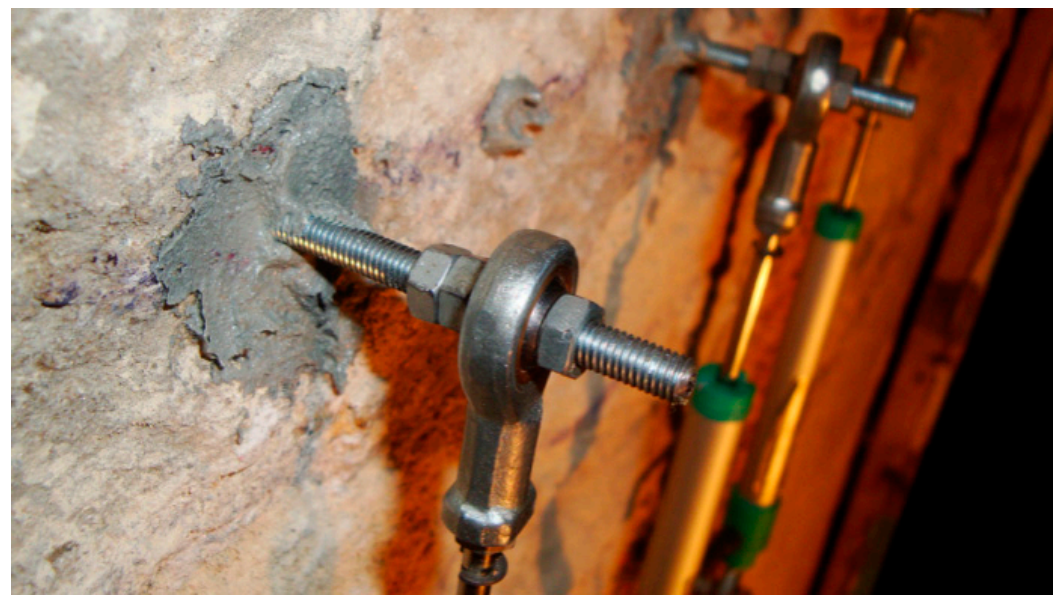

Figure 12. Displacement transducers attached to the wall.

Figure 13 shows the single flat-jack testing. As presented, three vertical reference alignments were considered. In order to estimate the effective flat-jack loaded area, the procedure proposed by Gregorczyk and Lourenço [29] was adopted: a sheet of carbon paper, sandwiched between two sheets of ordinary paper, was placed between the jack's surface and the surrounding masonry (this set was prepared in the shape of the jack). In this way, the areas where the jack comes into contact with the masonry are marked in the paper and can be measured (Figure 14).

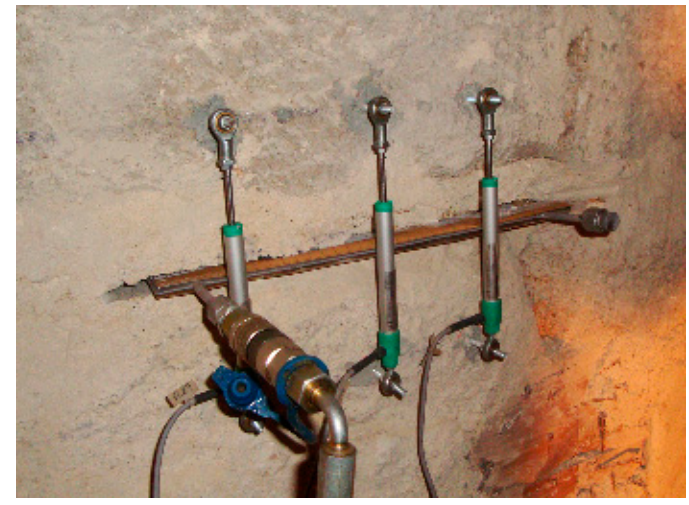

(a)

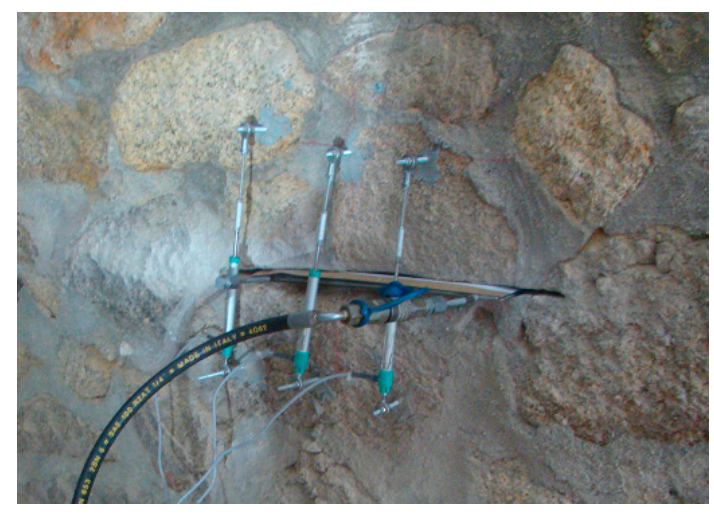

(b)

Figure 13. Single flat-jack testing: (a) conducted in the Órfeão de Viseu and (b) in the Águas de Viseu (b).
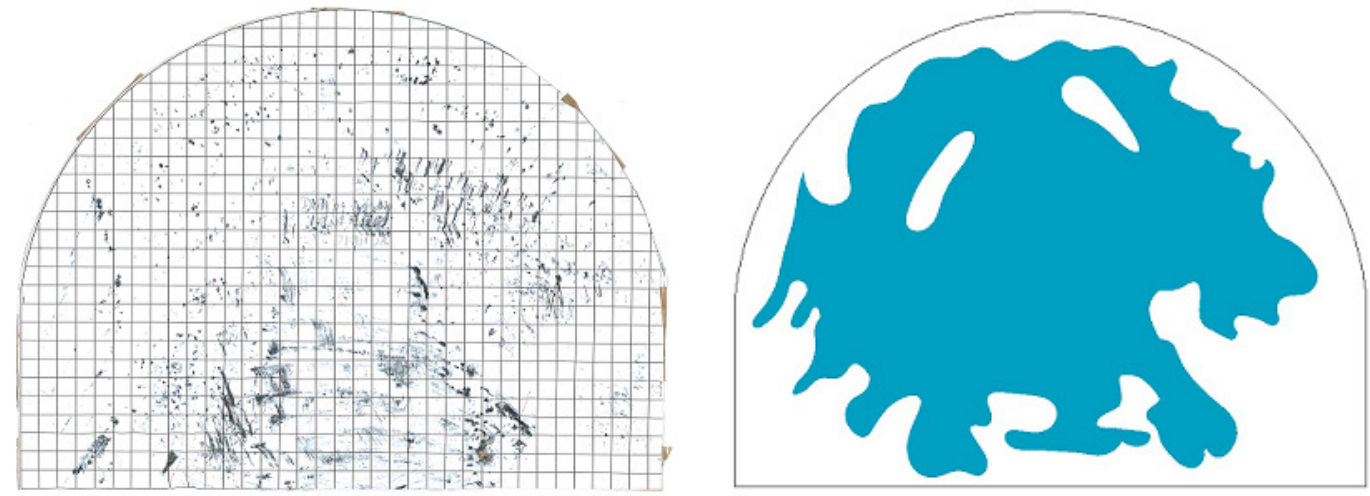

Figure 14. Contact area between the flat-jack and surrounding masonry. 
Due to the manifest poor condition of some of the carbon papers after removing of the flat-jacks and considering the deformation visible in the flat-jacks, in those cases, coefficient $\mathrm{k}_{\mathrm{a}}$ was estimated based on visual observation.

It is important to mention that, although humidity and temperature of the walls can slightly affect the results [13], such conditions were not possible to control during the tests.

Usually, the initial distance between reference points is not attained simultaneously in the various alignments. This is due, among other factors, to different stone and mortar distributions (areas with a larger proportion of mortar will sustain greater deformation, comparatively to others with a greater quantity of stone). To take this into account, the stress level that restores the initial wall geometry was assumed to be the average of the values that do so in the various alignments. Double flat-jack tests were conducted in the same areas where single flat-jacks had already been conducted, thus taking advantage of the existing cut. Figure 15 shows the double flat-jack testing being conducted.

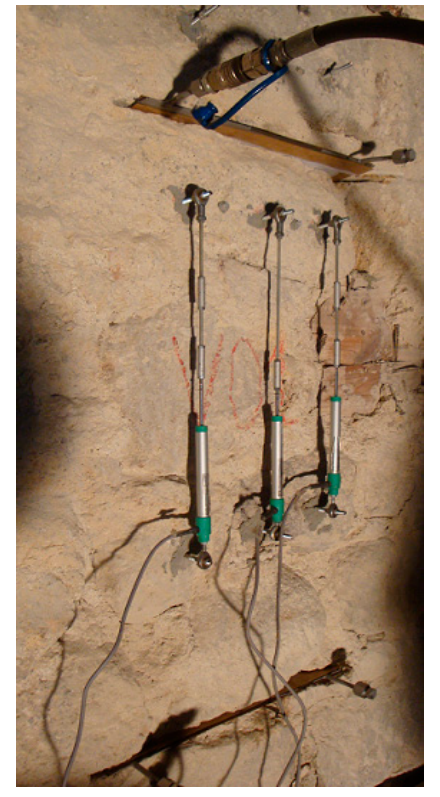

(a)

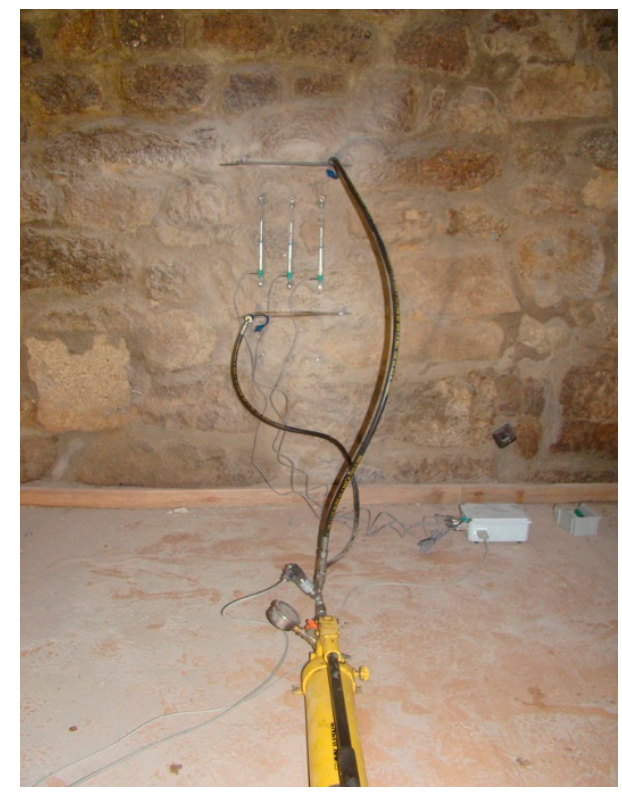

(b)

Figure 15. Double flat jack testing conducted in Orfeão de Viseu (a) and in Águas de Viseu (b).

\section{Results and Data Interpretation}

Two single flat-jack tests and one double flat-jack test were conducted in Orfeão de Viseu, whereas one single flat-jack test and two double flat-jack tests were conducted in Águas de Viseu. Tests are named according to the buildings (O—Orfeão de Viseu; A—Águas de Viseu) and type of test (S-single flat-jack test; D—double flat-jack test). Figures 16-18 show the evolution of the relative displacements in the different alignments, depending on the flat-jack pressure and the estimation of the corresponding in situ stress level, for all tests conducted. Pressure increments of $0.5 \mathrm{MPa}$, corresponding to 5 bar, were applied in the double flat-jack tests.

From the displacement results, the in-plane stress is estimated by the average of the four deformation measurements obtained from the three alignments. In the case of the Orfeão de Viseu, the low deviance of the displacement readings is a good indicator of the test evolution. Lower values for the single flat-jack test OS1 and OS2 where obtained since the test was carried out on first floor. As for the Águas de Viseu, the test was carried out on the ground floor, which is why the in situ stress value are higher than those obtained in Orfeão de Viseu. Moreover, in the case of Águas de Viseu the displacement readings were more variable. 


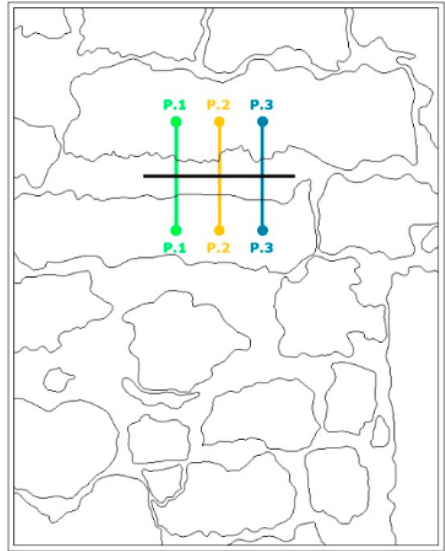

(a)

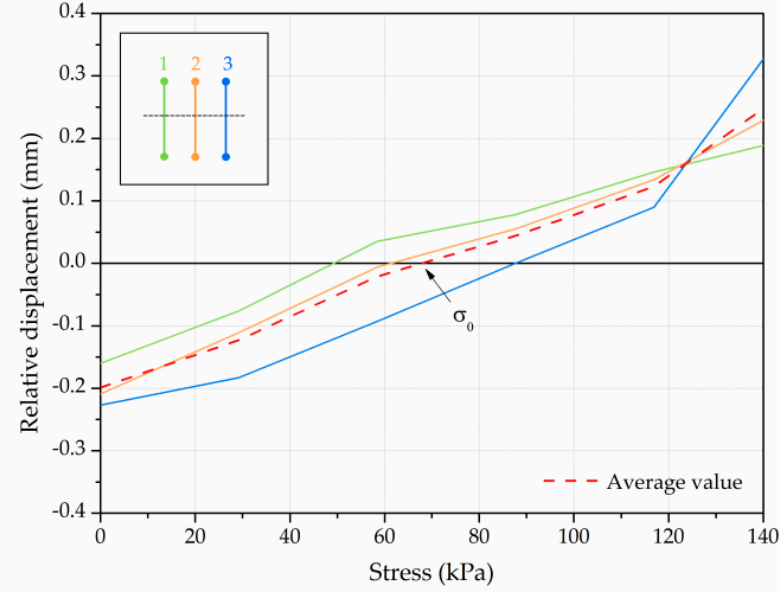

(b)

Figure 16. Single flat-jack test OS1: (a) identification of the vertical alignments; (b) evolution of the relative displacements for each vertical alignment and estimation of the in-situ stress.

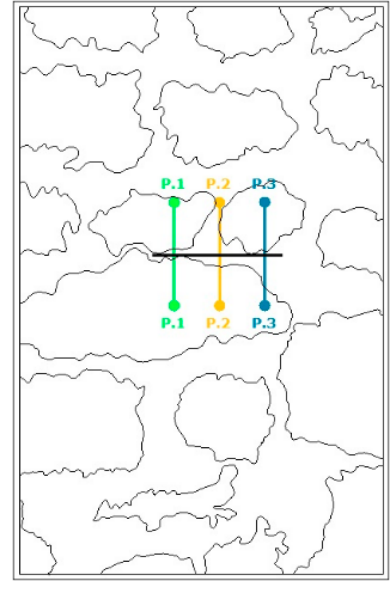

(a)

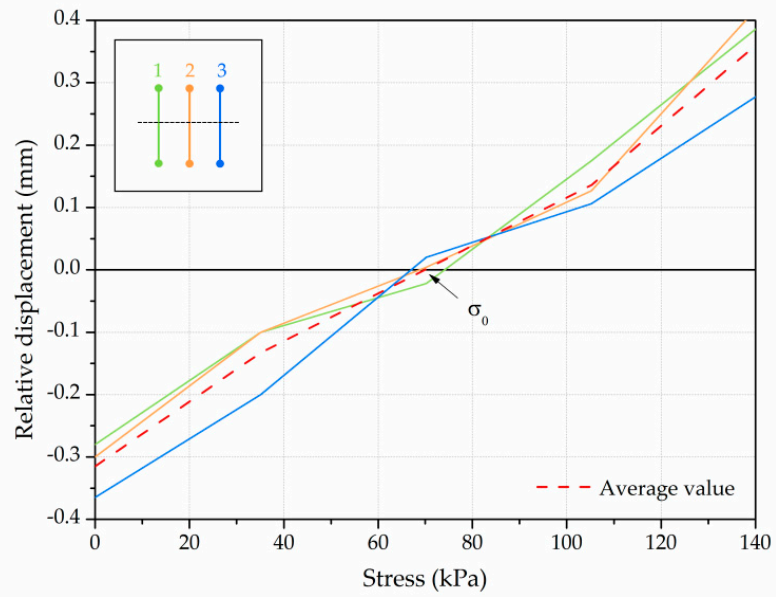

(b)

Figure 17. Single flat-jack test OS2: (a) identification of the vertical alignments; (b) evolution of the relative displacements for each vertical alignment and estimation of the in-situ stress.

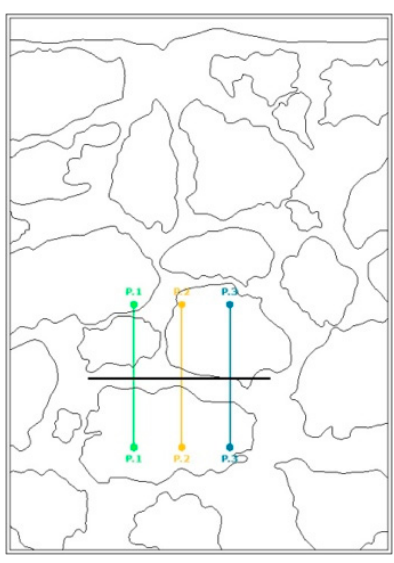

(a)

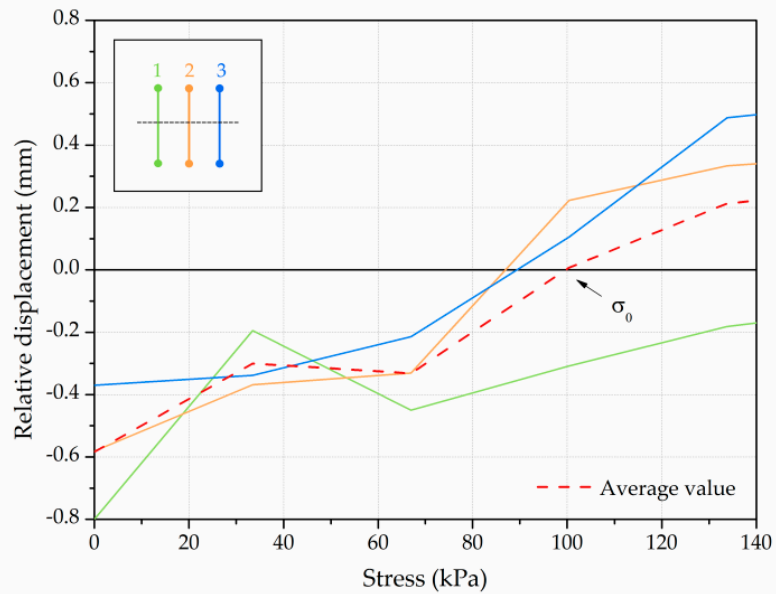

(b)

Figure 18. Single flat-jack test AS1: (a) identification of the vertical alignments; (b) evolution of the relative displacements for each vertical alignment and estimation of the in-situ stress. 
Figures 19-21 present the average stress-strain curves obtained for the double flat-jack tests conducted for the same walls and locations. For both buildings, failure was not reached and the maximum stress values attained range between 0.75 to $1.0 \mathrm{MPa}$. For the three tests, the masonry presented a high percentage of stone in the tested areas and also good fabric, even though there were generalized small dimensions and irregular stone blocks used. In the case of test AD1, this location revealed lower deformability in comparison to the other tested locations.

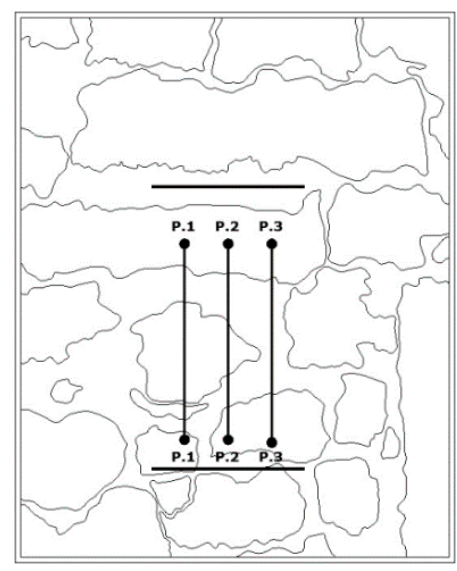

(a)

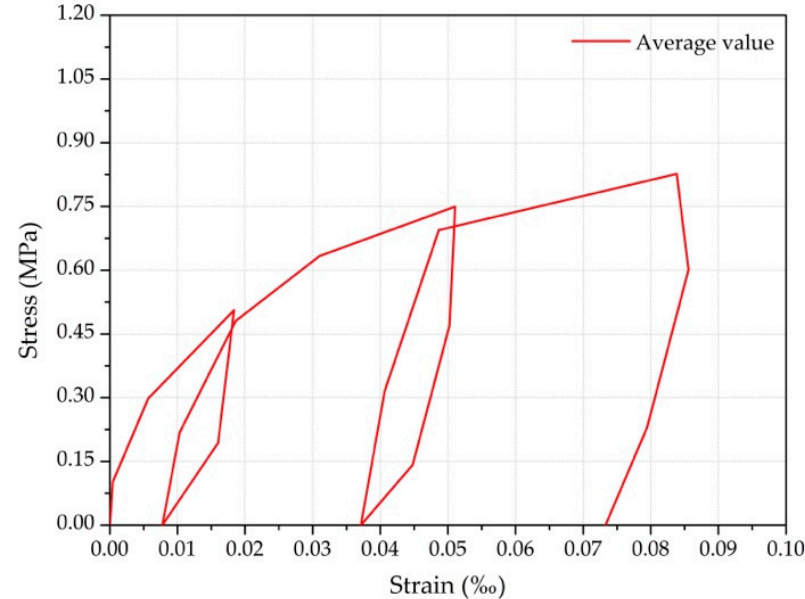

(b)

Figure 19. Double flat-jack test OD1: stress-strain curve.

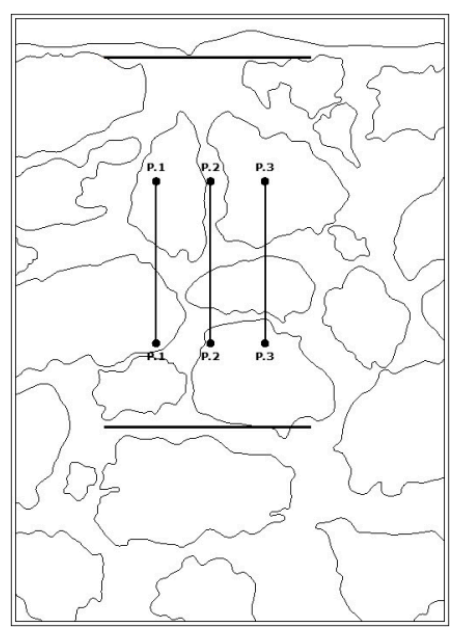

(a)

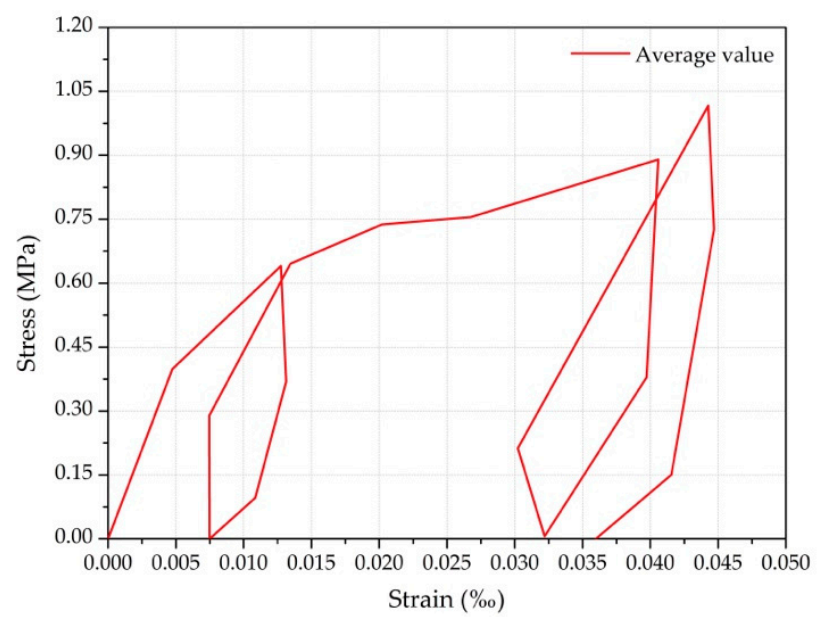

(b)

Figure 20. Double flat-jack test AD1: (a) identification of the vertical alignments; (b) average stress-strain curve.

Table 2 shows the estimated in situ stress that was obtained in the single flat-jack tests, and the maximum stress applied (which represents a lower limit of the wall's compressive strength). As one can understand from the analysis of the values given in Table 1, in the case of Orfeão de Viseu, the value of maximum stress recorded in the double flat-jack test is more than 10 times higher than those determined in the single flat-jack test, which is revealing of the high compressive safety level that these structures generally present. 


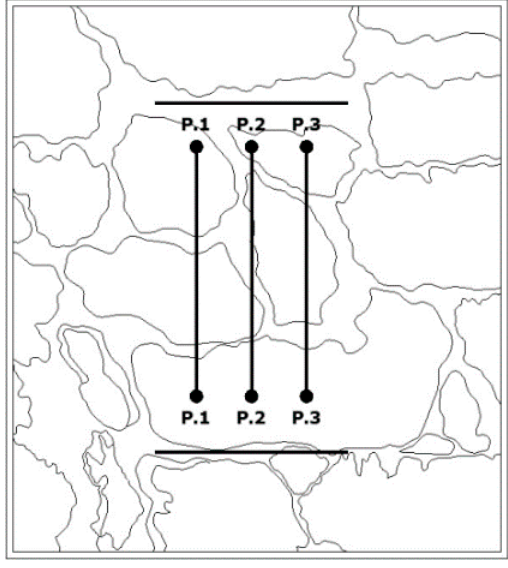

(a)

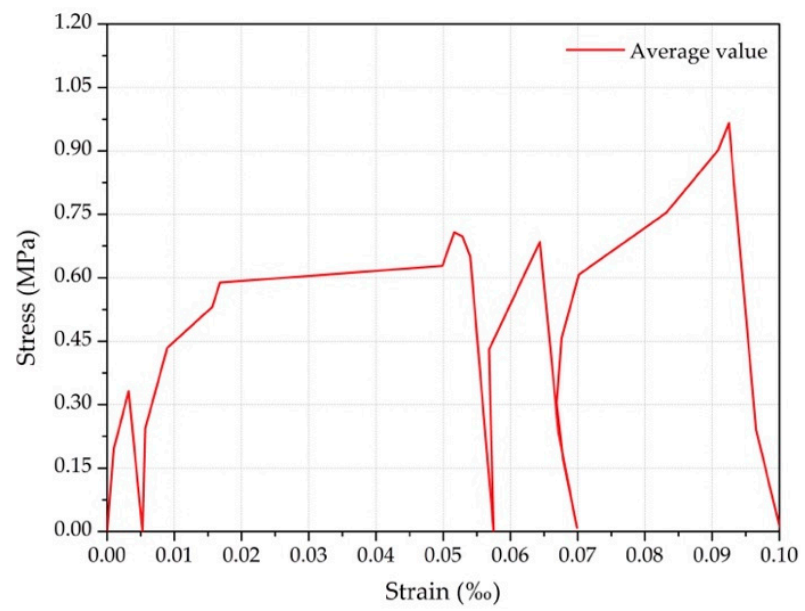

(b)

Figure 21. Double flat-jack test AD2: (a) identification of the vertical alignments; (b) average stress-strain curve.

Table 2. Flat-jack test results (in situ stress).

\begin{tabular}{ccccccc}
\hline & \multicolumn{3}{c}{ Orfeão de Viseu } & \multicolumn{3}{c}{ Águas de Viseu } \\
\hline & OS1 & OS2 & OD1 & AS1 & AD1 & AD2 \\
in situ stress $(\mathrm{kPa})$ & 68 & 70 & - & 99 & - & - \\
Maximum stress $(\mathrm{kPa})$ & - & - & 915 & - & 1098 & 1119 \\
\hline
\end{tabular}

The Young's modulus was obtained through graphical analysis, taking into account the slope of the stress-strain curves, namely the slope of the secant stiffness. Different portions of the curve (corresponding to different percentages of the maximum strength) can be analyzed, leading to different values for the Young's modulus. Figure 22 presents the different options for evaluation of the Young's modulus that were considered in this paper.

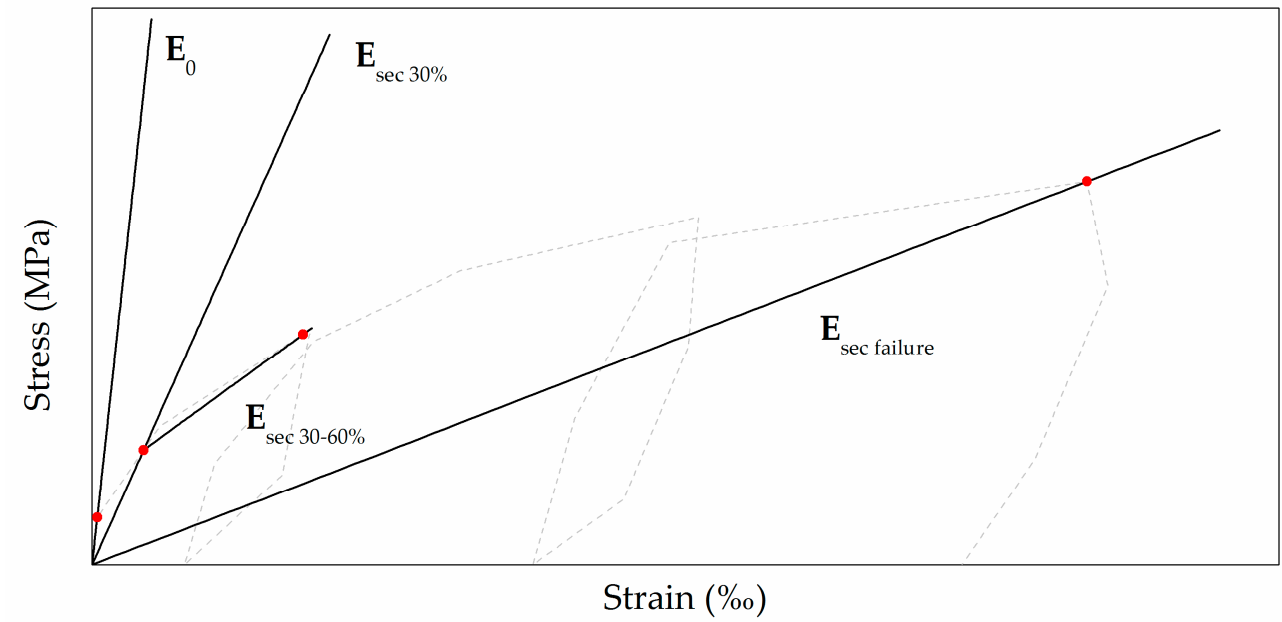

Figure 22. Representation of the different Young's modulus.

Table 3 presents the estimation of the values for the different Young's modulus that were computed, with a $15 \%$ reduction coefficient [26].

Regarding these values, it is important to stress here that several authors and code documents suggest that they can be affected by a non-neglectable variation resulting from the lateral confinement 
conditions of the masonry portion tested. ASTM standard C197-91 [25], RILEM TC 76-LUM [30], Binda [31], Noland et al. [32], all refer to variations for in situ stress up to $24 \%$, overestimation of maximum stress of about $15 \%$ and overestimation from 10 to $20 \%$ of the elastic modulus.

Table 3. Flat-jack test results (Young's modulus).

\begin{tabular}{ccccccc}
\hline Building & \multicolumn{3}{c}{ Orfeão de Viseu } & \multicolumn{3}{c}{ Águas de Viseu } \\
\hline Flat-jack Test & OS1 & OS2 & OD1 & AS1 & AD1 & AD2 \\
\hline $\mathrm{E}_{0}(\mathrm{MPa})$ & - & - & 1994 & - & 833 & 1716 \\
$\mathrm{E}_{\mathrm{sec} 30 \%}(\mathrm{MPa})$ & - & - & 486 & - & 833 & 983 \\
$\mathrm{E}_{\mathrm{sec} 30-60 \%}(\mathrm{MPa})$ & - & - & 157 & - & 319 & 175 \\
$\mathrm{E}_{\mathrm{sec} \text { failure }}(\mathrm{MPa})$ & - & - & 84 & - & 195 & 89 \\
\hline
\end{tabular}

Finally, Table 4 presents the values of maximum stress applied and Young's modulus obtained in other experimental campaigns aiming at characterizing granite stone masonry walls in the North of Portugal, in situ [3] and in laboratory, conducted in wall panels collected from existing buildings [6].

Table 4. Granite stone masonry experimental campaigns results.

\begin{tabular}{ccc}
\hline Experimental Campaign & Maximum Stress (kPa) & Young's Modulus (MPa) \\
\hline Miranda, 2011 [3] & $49-840$ & $800-3300$ \\
Almeida, 2013 [6] & $2500-3940$ & $220-320$ \\
\hline
\end{tabular}

As can be observed, the values obtained in the experimental campaign presented herein are consistent with those reported by other authors for granite stone masonry walls in Portugal. Nevertheless, it must be recalled that some typological differences exist between the walls studied in this paper and in those campaigns, namely, in what concerns the number of leaves and their connection level. This feature must be taken in account when comparing mechanical properties. In fact, the studies by Miranda [3] and Almeida [6] mentioned above concern walls typical from the old urban center of Porto, representing a peculiar typology, based on granite stones with medium to large dimensions (with a diagonal length up to $1.10 \mathrm{~m}$ ), and assembled in roughly horizontal alignments. As to the construction technique, stones are first put in place and only then is mortar applied along the stone's border. This represents a constructive process unique to a specific geography, and the results obtained in those walls are not easily extrapolated to stone masonry walls from different areas in Northern Portugal. This peculiarity reinforces the pioneering character of the research described in this paper.

\section{Conclusions}

The work presented in this paper intends to offer a contribution to the typological and mechanical characterization of granite stone masonry walls frequent in the Portuguese old urban centers. With this intent, an in situ characterization campaign was carried out in the old city center of Viseu, Portugal, under the scope of which two traditional stone masonry buildings were used as case studies. From this experimental campaign, some general conclusions can be drawn:

Flat-jack testing is a relatively simple and economical testing procedure that is extremely useful in in situ characterization of stone masonry walls. In fact, as discussed in this manuscript, the level of rigor achieved with this technique is clearly consistent with that needed for practical rehabilitation or strengthening interventions $[23,33]$. It must nevertheless be mentioned that a skilled operator is necessary in order to guarantee the desired reliability.

Moreover, when dealing with irregular stone masonry walls, the difficulty in following all the requirements stated in the standards are evident. Among these, one must mention the difficulty in locating a suitable area to open the cuts (preferably a horizontal joint, difficult to locate with a suitable extension in this kind of masonry), the dimension of the stones (which conditions the dimension of the 
jacks to be used), the possibility that the cutting releases filling fragments (which affects the original load paths) or causes local stone crushing, and the difficulty in positioning the displacement measuring equipment. All of this introduces subjectivity in the results interpretation procedure. A uniformized flat-jack testing procedure suitable for application in irregular stone masonry walls is thus desirable in order to guarantee that not only are the values obtained representative of the wall, but also that values resulting from different campaigns are comparable [14,34,35].

Determining the effective area of the flat-jack in contact with the masonry is determined to be a decisive conditioner of the results' reliability. Some considerations on the adopted procedure are thus desirable. It was found that, besides requiring sensitivity from the analyst and thus being thus open to subjectivity, this procedure presents the disadvantage that the flat-jack removal may damage the carbon paper set, thus rendering its analysis even more difficult. Estimating the effective loaded area and resorting to visual observation of the jack, after its removal, can be a suitable alternative. On the other hand, and even when it is possible to keep the integrity of the carbon papers during flat-jack removal, this operation may cause the marking of areas exclusively derived from this procedure, and not from the jack pressurizing, resulting in underestimated stress values.

Regarding the use of this experimental technique to characterize specific type of masonry (granite stone masonry), it is worth noting that due to the characteristics of these walls, there is often the need to resort to heavy techniques/equipment to remove the flat-jacks or the cutting equipment from the wall, leading to the disassembly of the testing area. In some cases, the damage suffered by the walls as a result of these operations is clearly unacceptable. Furthermore, when the disassembling is required during the slot cutting, conducting the flat-jack test becomes altogether impossible.

The relationship between stress values measured from the single flat-jack test and maximum stress attained for each test site are indicators of the level of safety of the masonry tested in respect to vertical loading. The test results show that maximum stress values are considerably higher than the in situ stress, which leads to high safety factors (ratio between maximum stress value reached and the in situ stress) in respect to vertical actions, characteristic feature of this type of masonry, with a ratio between 11 and 13.

As a final note, the authors would like to underline that this work reports and discusses a first study of this kind conducted in the old urban center of Viseu, so further characterization campaigns are encouraged in order to improve the reliability of the assumptions made and to validate some of the results and conclusions presented.

Author Contributions: All authors contributed to every part of the research described in this paper.

Funding: This research received no external funding.

Acknowledgments: This research was carried out in the scope of the project "Viseu Património". The authors wish to thank the support of the Viseu City Council, through the Urban Rehabilitation Society Viseu Novo. Engineer Jorge Fonseca is gratefully acknowledged for his contribution in the experimental component of the campaign. The constructive comments and suggestions provided by the two anonymous reviewers are also acknowledged by the authors.

Conflicts of Interest: The authors declare no conflict of interest.

\section{References}

1. ICOMOS. ICOMOS Chapter-Principles for the Analysis, Conservation and Structural Restoration of Architectural Heritage; International Council on Monuments and Sites (ICOMOS): Paris, France, 2003.

2. Sousa, L. Caraterização e Parametrização de Paredes Portantes de Alvenarias de Pedra Quanto à Regularidade Geométrica no seu Plano. Master's Thesis, Universidade do Porto, Porto, Portugal, 2010.

3. Miranda, L. Ensaios Acústicos e de Macacos Planos em Alvenarias Resistentes. Ph.D. Thesis, Universidade do Porto, Porto, Portugal, 2011.

4. Vasconcelos, G. Experimental Investigations on the Mechanics of Stone Masonry: Characterization of Granites and Behavior of Ancient Masonry Shear Walls. Ph.D. Thesis, Universidade do Minho, Guimarães, Portugal, 2005. 
5. Oliveira, D.; Lourenço, P.B. Experimental Behaviour of Three-Leaf Stone Masonry Walls. In Proceedings of the "The Construction Aspects of Built Heritage Protection" Conference and Brokerage Event, Dubrovnik, Croatia, 14-17 October 2006; Radić, J., Rajčić, V., Žarnić, R., Eds.; European Construction Technology Platform: Brussels, Belgium, 2006; pp. 356-362.

6. Almeida, C. Paredes de Alvenaria do Porto: Tipificação e Caraterização Experimental. Ph.D. Thesis, Universidade do Porto, Porto, Portugal, 2013.

7. Ferreira, T.; Costa, A.A.; Arêde, A.; Gomes, A.; Costa, A. Experimental characterization of the out-of-plane performance of regular stone masonry walls, including test setups and axial load influence. Bull. Earthq. Eng. 2015, 13, 2667-2692. [CrossRef]

8. Instituto Nacional de Estatística. Censos 2011 Resultados Definitivos-Centro; Instituto Nacional de Estatística (INE), I.P.: Lisboa, Portugal, 2012.

9. $\quad$ Aragão, M. Viseu, Instituições Sociais; Seara Nova: Lisbon, Portugal, 1936.

10. IPQ. NP EN 1926. Métodos de Ensaio Para Pedra Natural. Determinação da Resistência à Compressão (Natural Stone Test Methods. Determination of Compressive Strength); Instituto Português da Qualidade (Portuguese Institute for Quality): Caparica, Portugal, 2000.

11. Casella, G. Gramáticas de Pedra. Levantamento de Tipologias de Construção Murária; Centro Regional de Artes Tradicionais: Porto, Portugal, 2003.

12. Bell, F. Engineering Geolog; Elsevier: Oxford, UK, 2007.

13. Vicente, R.; Ferreira, T.; Mendes da Silva, J.; Varum, H. In situ flat-jack testing of traditional masonry walls: Case study of the old city center of Coimbra, Portugal. Int. J. Archit. Herit. 2015, 9, 794-810. [CrossRef]

14. Cescatti, E.; Dalla Benetta, M.; Modena, C.; Casarin, F. Analysis and evaluations of flat jack test on a wide existing masonry buildings sample. In Proceedings of the 16th International Brick and Block Masonry Conference, Padova, Italy, 26-30 June 2016; Modena, C., da Porto, F., Valluzzi, M.R., Eds.; CRC Press: Boca Raton, FL, USA, 2016; pp. 1485-1491.

15. Binda, L.; Tiraboschi, C. Flat-jack test as a slightly destructive technique for the diagnosis of brick and stone masonry structures. Int. J. Restor. Build. Monum. 1999, 5, 449-472.

16. Uranjek, M.; Bosiljkov, V.; Žarnić, R.; Bokan-Bosiljkov, V. In situ tests and seismic assessment of a stone-masonry building. Mater. Struct. 2012, 45, 861-879. [CrossRef]

17. Lombillo, I.; Thomas, C.; Villegas, L.; Fernández-Álvarez, J.; Norambuena-Contreras, J. Mechanical characterization of rubble stone masonry walls using non and minor destructive tests. Constr. Build. Mater. 2013, 43, 266-277. [CrossRef]

18. Andreini, M.; de Falco, A.; Giresini, L.; Sassu, M. Mechanical characterization of masonry walls with chaotic texture: Procedures and results of in-situ tests. Int. J. Archit. Herit. 2014, 8, 376-407. [CrossRef]

19. Simões, A.; Bento, R.; Gago, A.; Lopes, M. Mechanical characterization of masonry walls with flat-jack tests. Exp. Tech. 2016, 40, 1163-1178. [CrossRef]

20. Gelmi, C.; Modena, C.; Rossi, P.P.; Zaninetti, A. Mechanical characterization of stone masonry structures in old urban nuclei. In Proceedings of the 6th North American Masonry Conference, Philadelphia, PA, USA, 6-9 June 1993; Hamid, A.A., Harris, H.G., Eds.; The Masonry Society: Longmont, CO, USA, 1993; pp. 505-516.

21. Roque, J. Reabilitação estrutural de paredes antigas de alvenaria. Master's Thesis, Universidade do Minho, Guimarães, Portugal, 2002.

22. Pagaimo, F. Caracterização morfológica e mecânica de alvenarias antigas: Caso de estudo da vila histórica de Tentúgal. Master's Thesis, Universidade de Coimbra, Coimbra, Portugal, 2004.

23. Ferreira, T. Avaliação da vulnerabilidade sísmica de núcleos urbanos antigos: Aplicação ao núcleo urbano antigo do Seixal. Advanced Studies Thesis in Rehabilitation of Built Heritage, Universidade do Porto, Porto, Portugal, 2010.

24. ASTM. ASTM C 1196-91: Standard Test ASTM C1196-91, Standard Test Method for in Situ Measurement of Masonry Deformability Properties Using the Flatjack Metho; ASTM: West Conshohocken, PA, USA, 1991.

25. ASTM. ASTM C 1197-91: Standard Test ASTM C1197-91, In-Situ Compressive Stress within Solid Unit Masonry Estimated Using Flat-Jack Measurements; ASTM: West Conshohocken, PA, USA, 1991.

26. RILEM. RILEM Recommendation MDT.D.4: In-situ stress tests based on the flat jack. International union of laboratories and experts in construction materials, systems and structures (RILEM), RILEM TC 177-MDT: Masonry durability and on-site testing. Mater. Struct. 2004, 37, 491-496. [CrossRef] 
27. RILEM. RILEM Recommendation MDT.D.5: In-situ stress-strain behaviour tests based on the flat jack. International union of laboratories and experts in construction materials, systems and structures (RILEM), RILEM TC 177-MDT: Masonry durability and on-site testing. Mater. Struct. 2004, 37, 497-501. [CrossRef]

28. LabView SignalExpress; National Instruments: Austin, TX, USA, 2010.

29. Gregorczyk, P.; Lourenço, P.B. A review on flat-jack testing. Engenharia Civ. 2000, 9, 39-50.

30. De Vekey, R.C. General recommendations for methods of testing load-bearing unit masonry. Mater. Struct. 1988, 21, 229-231. [CrossRef]

31. Binda, L. Sonic tomography and flat-jack tests as complementary investigation procedures for the stone pillars of the temple of S. Nicolò l'Arena (Italy). NDT E Int. 2003, 36, 215-227. [CrossRef]

32. Noland, J.; Atkinson, R.; Schuller, M. A review of the flat-jack method for nondestructive evaluation. In Proceedings of the Nondestructive Evaluation of Civil Structures and Materials, Boulder, CO, USA, 15-17 October 1990.

33. Santhakumar, A.R.; Mathews, M.S.; Thirumurugan, S.; Uma, R. Seismic Retrofitting of Historic Masonry Buildings-Case Study. Adv. Mater. Res. 2010, 133, 991-996. [CrossRef]

34. Giordano, A.; Cascardi, A.; Micelli, F.; Aiello, M.A. Theoretical study for the strengthening of a series of vaults in a cultural heritage masonry building: A case study in Italy. In Proceedings of the 10th International Masonry Conference (10IMC), Milan, Italy, 9-11 July 2018; pp. 2510-2531.

35. La Mendola, L.; Lo Giudice, E.; Minafò, G. Experimental calibration of flat jacks for in-situ testing of masonry. Int. J. Archit. Herit. 2018, 1-11. [CrossRef]

(C) 2019 by the authors. Licensee MDPI, Basel, Switzerland. This article is an open access article distributed under the terms and conditions of the Creative Commons Attribution (CC BY) license (http://creativecommons.org/licenses/by/4.0/). 